\title{
Macrovascular complication in diabetes and evidence for the treatment \& CVD risk reduction
}

\begin{abstract}
Diabetes mellitus (DM) is a metabolic disease presents with elevated blood glucose levels and by microvascular \& macrovascular manifestations and results in a significant increase in the morbidity and mortality Morris et al. ${ }^{1}$ Type II DM Manifest by relative insulin lack and/or insulin resistance major Type of Diabetes in Population, usually middle age but now manifest in youths also. The cause for this is attributed, to an age of the population and the increasing prevalence of metabolic syndrome overweight, obesity and sedentary lifestyles. Type I DM is insulin-dependent diabetes mellitus is Manifest by a mostly by exogenous insulin for life long, and type I DM patients are prone to microvascular complications, including nephropathy, retinopathy \& neuropathy and to macrovascular disease CAD and peripheral vascular disease PVD, Mortality in type I DM has increased 4-7 folds compared to matched nondiabetic population, and $\mathrm{CAD}$ and nephropathy are the main causes of death. $^{2}$
\end{abstract}

Volume 6 Issue 4 - 2019

\author{
Rajesh Jain,' Susanne Olejas, ${ }^{2}$ Amit Chauhan, ${ }^{2}$ \\ Rachna Jain, ${ }^{2}$ Reza Shoghli, ${ }^{2}$ Alexander \\ Edwards, ${ }^{2}$ Ibina Abigo, ${ }^{2}$ Wioleta Zietek, ${ }^{2}$ \\ Zoonifer Khan, ${ }^{2}$ Satrupa Ragoonanan, ${ }^{2}$ Nisha \\ Benoy $^{2}$ \\ 'Diabetes Prevention Control Project, National health Mission, \\ India \\ ${ }^{2}$ World Diabetes Foundation, Denmark
}

\begin{abstract}
Correspondence: Rajesh Jain, Diabetes Prevention Control Project, National health Mission with World Diabetes Foundation, Denmark. 108 B Gandhi Gram, Vinobha Nagar, Kanpur, UP, India, Email drrajeshjai@diabetesasia.org
\end{abstract}

Received: September 19, 2019 | Published: December 30, 2019
Cardiovascular complication risk in Type II Diabetes is common in different categories as follows

In asymptomatic cardiovascular disease in type II diabetes is $2 / 3$ times more compare to non-diabetes Ingelsson et al., ${ }^{3} 2 / 3$ deaths due to CVD and HF is more in Type II Diabetes than Non-Diabetes Low, et al. ${ }^{4}$ CVD manifestation is 15 years earlier in Type II Diabetes than Non-Diabetes Dandamudi et al. ${ }^{5}$ Heart failure HF develops 2.5-5 times in Diabetes compared to non-diabetes Low et al. ${ }^{4}$ Left ventricular (LF) dysfunction is 2 times more common in diabetes Dandamudi et al. ${ }^{5}$ In CKD with Type II Diabetes CV Mortality increases (Figure 1) to 2.9 folds Afkarian et al. ${ }^{6}$ In the case of male 60 Years, Life Expectancy is reduced by 12 years in Patients of Diabetes with Previous CVD, In this case, CVD is represented by MI or stroke, and life expectancy reduced by 6 years in case of diabetes without CVD Anglelantome et al. ${ }^{7}$ Nurses' Health Study RRs of MI or Stroke Event according to DM Status Frank et al. ${ }^{8}$ (Figure 2) CV Death Reduction in Various Landmark Trials Bajaj et al. ${ }^{9}$

\section{Despite Advances in Therapies, Life Expectancy is reduced by Multiple Morbidities of T2DM, Stroke and MI}

\section{All-cause mortality by disease status of Participants at baseline}

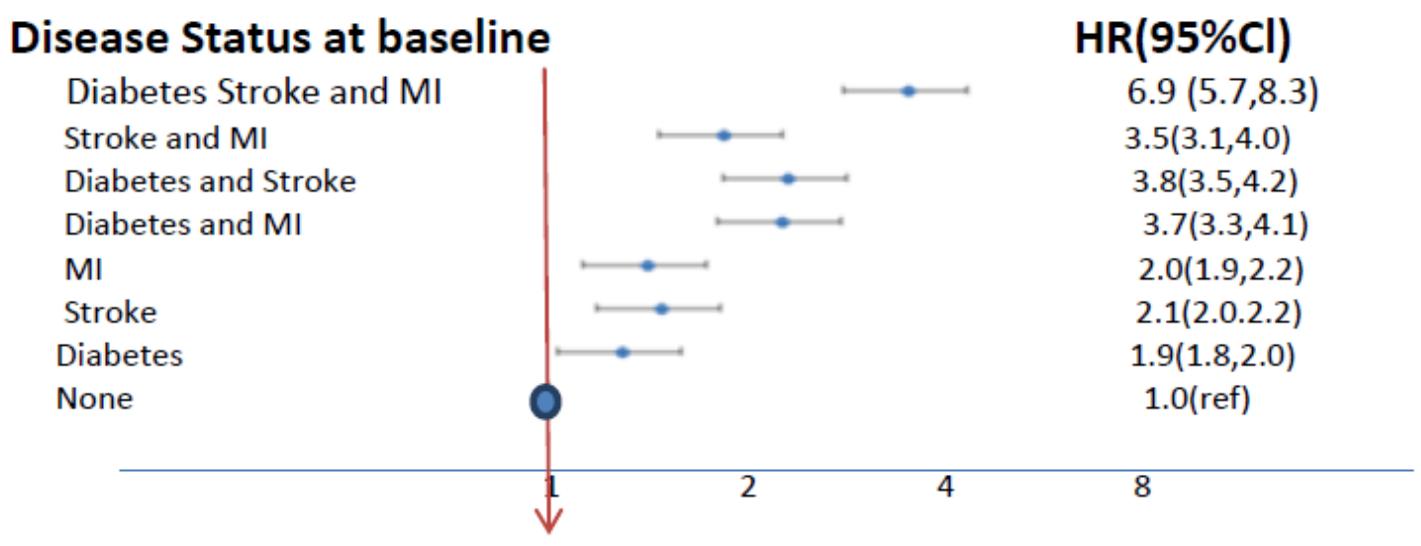

Figure I Nurses' Health Study RRs of MI or Stroke Event according to DM Status. ${ }^{8}$ 


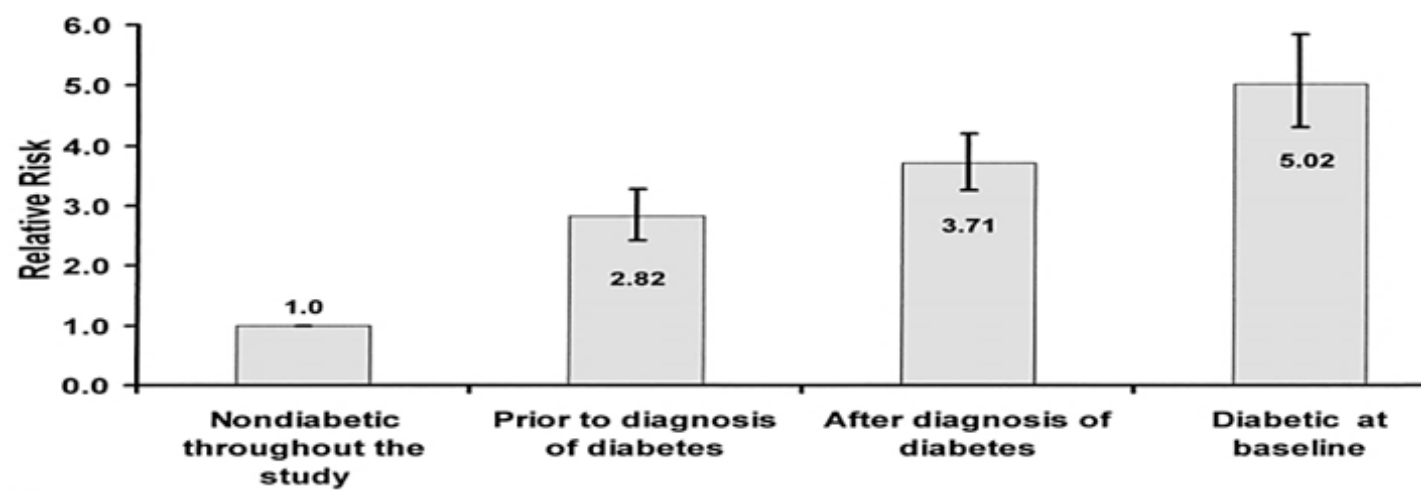

Figure $2 \mathrm{CV}$ death reduction in various landmark Trials. ${ }^{9}$

The patients with T2DM, but without a history of myocardial infarction, had a similar risk of myocardial infarction compared to patients with a previous myocardial infarction has established that Type 2 Diabetes Mellitus is Coronary Heart Disease equivalent. The common Soil hypothesis suggested that large vessel atherosclerosis can precede the development of diabetes suggested that rather than being a complication of Diabetes both CVD \& Diabetes Spring from a Common Soil although the mechanism behind this nexus is not clear but the statistical association is well accepted. Elevated blood glucose levels have been associated with higher cardiovascular risk. The co-existence of CVD \& T2DM has led to a Paradigm Shift in the management approach of diabetes as from several decades it is believed that that improving glycemic conditions and traditional risk factors would lower cardiovascular risk in T2DM but despite the achievement of Glycemic Control with Diabetes medications the Macrovascular outcome remains very controversial.

Among patients with type 2 diabetes who have established ASCVD, SGLT2inhibitors or GLP-1receptor agonists with evidence of cardiovascular benefit are advocated by USFDA and endorsed by ADA as part of Glycaemic management; CVD benefit means it has a label indication for reducing CVD events. In CVD with HF coexists, SGLT2 inhibitors are recommended.

For patients with T2DM and CKD, with or without CVD, consider the use of SGLT2 inhibitors were shown to reduce CKD progression or, if contraindicated or not preferred a GLP-1 receptor agonist shown to reduce CKD progression (Tables 1\&2).

Table I Cardiovascular death

\begin{tabular}{|c|c|c|c|c|c|}
\hline Trial & Study Drug & $\begin{array}{l}\text { Median } \\
\text { Years }\end{array}$ & Cardivascular Death & HR (95\% Cl) & NNT \\
\hline I.Empa-Reg & Empaglfozin & 3.1 & $\%$ & $0.62(0.49-0.77)$ & 46 \\
\hline 2.Leader & Liraglutide & 3.8 & rar & $0.78(0.66-0.93)$ & 77 \\
\hline $3.4 \mathrm{~S}$ & Simvastin & 5.4 & $\mathrm{COH}$ & $0.65(0.52-0.80)$ & 31 \\
\hline 4.CTT meat-analyst & $\begin{array}{l}26 \text { Statin } \\
\text { trials }\end{array}$ & 5.1 & 口 & $0.86(0.82-0.94)$ & NR \\
\hline 5.Hope & Ramipril & 5 & $\sigma$ & $0.74(0.64-0.87)$ & 50 \\
\hline 6.Solvd-Treatment & Enalapril & 3 & $\infty$ & $0.82(0.72-0.94)$ & 56 \\
\hline 7.Rales & Spirolactone & 2 & 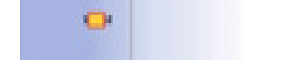 & $0.69 *(0.58-0.82)$ & 10 \\
\hline \multirow[t]{2}{*}{ 8.Paradigm } & $\begin{array}{l}\text { Sacubitril- } \\
\text { Valsartan }\end{array}$ & 27 months & 0 & $0.80(0.7 \mid-0.89)$ & 31 \\
\hline & Enalapril & & & & \\
\hline 9.Accord Trial & BP result & 4.7 Years & 0 & I.06(0.74-1.52) & \\
\hline
\end{tabular}

Table 2 Primary and Secondary Outcome:ACCORD Trail

\begin{tabular}{|c|c|c|c|c|c|c|}
\hline \multirow{2}{*}{ Outcome } & \multicolumn{2}{|c|}{$\begin{array}{l}\text { Intensive Therapy } \\
(\mathrm{N}=5 \mid 28)\end{array}$} & \multicolumn{2}{|c|}{$\begin{array}{l}\text { Standard Therapy } \\
(\mathrm{N}=5 \mid 23)\end{array}$} & \multirow{2}{*}{$\begin{array}{l}\text { Hazard Ratio } \\
(95 \% \mathrm{Cl})\end{array}$} & \multirow{2}{*}{$\begin{array}{l}\mathbf{P} \\
\text { Value }\end{array}$} \\
\hline & $\begin{array}{l}\text { no. of patients } \\
\text { (\%) }\end{array}$ & $\begin{array}{l}\% \text { per } \\
\text { yr }\end{array}$ & $\begin{array}{l}\text { no. of patients } \\
\text { (\%) }\end{array}$ & $\begin{array}{l}\% \text { per } \\
\text { yr }\end{array}$ & & \\
\hline Primary outcome & $352(6.9)$ & 2.11 & $37 \mid(7.2)$ & 2.29 & $0.90(0.78-1.04)$ & 0.16 \\
\hline
\end{tabular}




\begin{tabular}{|c|c|c|c|c|c|c|}
\hline \multirow{2}{*}{ Outcome } & \multicolumn{2}{|c|}{$\begin{array}{l}\text { Intensive Therapy } \\
(\mathrm{N}=5 \text { I 28) }\end{array}$} & \multicolumn{2}{|c|}{$\begin{array}{l}\text { Standard Therapy } \\
(\mathrm{N}=5 \mid 23)\end{array}$} & \multirow{2}{*}{$\begin{array}{l}\text { Hazard Ratio } \\
(95 \% \mathrm{Cl})\end{array}$} & \multirow{2}{*}{$\begin{array}{l}P \\
\text { Value }\end{array}$} \\
\hline & $\begin{array}{l}\text { no. of patients } \\
\text { (\%) }\end{array}$ & $\begin{array}{l}\% \text { per } \\
\text { yr }\end{array}$ & $\begin{array}{l}\text { no. of patients } \\
\text { (\%) }\end{array}$ & $\begin{array}{l}\% \text { per } \\
\text { yr }\end{array}$ & & \\
\hline \multicolumn{7}{|l|}{ Secondary outcome } \\
\hline \multicolumn{7}{|l|}{ Death } \\
\hline Any cause & $257(5.0)$ & 1.41 & $203(4.0)$ & 1.14 & $1.22(1.01-1.46)$ & 0.04 \\
\hline Cardiovascular causes & $135(2.6)$ & 0.79 & $94(1.8)$ & 0.56 & $1.35(1.04-1.76)$ & 0.02 \\
\hline Nonfatal myocardial infarction & $186(3.6)$ & 1.11 & $235(4.6)$ & 1.45 & $0.76(0.62-0.92)$ & 0.004 \\
\hline Nonfatal stroke & $67(1.3)$ & 0.39 & $61(1.2)$ & 0.37 & I.06 (0.75-I.50) & 0.74 \\
\hline $\begin{array}{l}\text { Fatal or nonfatal congestive heart } \\
\text { failure }\end{array}$ & $152(3.0)$ & 0.9 & $124(2.4)$ & 0.75 & I. $18(0.93-1.49)$ & 0.17 \\
\hline
\end{tabular}

ACCORD TRIAL: The result of the trial suggest that the risk of mortality (HR 1.22) and CVD death (HR, 1.35) with lack of benefit in primary CVD outcome or primary microvascular outcome forces the results that the ACCORD intensive regimen targeted at $\mathrm{HbA1C}$ below $6.0 \%$ is not a candidate for ACCORD-type High-Risk diabetic with poor glycemic legacy \& elderly more prone to Hypoglycemia. Example, a 70-year-old patient with Type 2 Diabetes for 12 years with a history of MI 6 years, and no significant microvascular complications \& $\mathrm{HbA} 1 \mathrm{C} 7.5 \%$. This type of patients is list likely benefit from strict control chew et al. ${ }^{10}$ In the ACCORD trial, the intensive therapy group had an increase in cardiovascular mortality (HR 1.35; 95\% CI 1.04; 1.76), but lower rates of nonfatal myocardial infarction (HR $0.76 ; 95 \%$ CI $0.62 ; 0.92$ ). ADVANCE Trial-The trial was started to reduce HBA1c level of $6.5 \%$ as intensive blood sugar control Protocol but results show that did not show reduction in major cardiovascular events. In ADVANCE trial Gliclazide MR was used to lower blood sugar to HBA1c $6.5 \%$ and no evidence exist that use increases mortality NIH. ${ }^{11}$ Intensive glucose control significantly decreases the outcome of major macrovascular or microvascular events, as a result of a decrease in nephropathy. The benefit given by the ADVANCE treatment trial was a $1 / 5^{\text {th }}$ reduction in renal complications, suggesting that strict control of glucose has a role in the prevention of microvascular complications of type II diabetes Gerstein et al. ${ }^{12}$

After the Controversy of Rosiglitazone in 2008, the US FDA Issued Guidance to all the Drug Manufacturer that dedicated CV safety of newer drugs must be established through a dedicated CV Safety Trial because of the huge burden of cardiovascular mortality and morbidity are highest in Diabetes. Since 2008 it was considered diabetes as CAD equivalent NCEP, ${ }^{13}$ or with double the risk of $\mathrm{CV}$ events. Several clinical trials with more strict blood sugar control versus moderate control result in mild to moderately reduced risk in Nonfatal MI Holman et al. ${ }^{14}$ Long term follow of UKPDS in type II Diabetes suggested legacy effects of good glycaemic control but there was increased CV mortality in strict blood sugar control in ACCORD Gerstein et al., ${ }^{12}$ trial \& No decrease in mortality in VADT Trial Duckworth et al. ${ }^{15}$ In this trial, most of the participants were older and at high-risk CV patients. DDP-4 inhibitors CV Safety Study-SAVOR TIMI with Saxagliptin was the first CVOT after rosiglitazone in this trial Saxagliptin has achieved its primary endpoint which was no inferiority of 3P MACE vs Placebo, however, there is $27 \%$ statistically significant increase in HHF has raised a very vital concern. The similar finding of Alogliptin in the EXAMINE trial has strengthened the neutral CV outcome with a similar increase in HHF signal like Saxagliptin. TECOS Trial with Sitagliptin has shown that Sitagliptin is CV Safe with no increase in HHF signal. The CARMELINA trial with Linagliptin reaffirms the finding of the TECOS trial; there is no discrepancy in CV safety as well as HHF with Linagliptin as per FDA requirement. But in CAROLINA Trial the CV safety outcome of Linagliptin in less CV risk population was similar to Glimepiride. So for CV safety of All DPP4 inhibitors available in the USA is well established with the advantage of Lower risk of Hypoglycemia and less weight gain concern.

EMPA REG outcome trial Zinman et al., ${ }^{16}$ with empagliflozin versus placebo in high-risk diabetes patients were observed for 3.1 years, two doses of $25 \mathrm{mg}$ and $10 \mathrm{mg}$ used. The primary outcome was 3P MACE, Empagliflozin has shown 14\%, significant relative risk reduction in 3P MACE as compared to Placebo, The HR for $\mathrm{CV}$ death was 0.62 with very persuasive $\mathrm{p}$ value $<.0001$ which means Empagliflozin offers 38\% RRR in CV death as compared to Placebo the All-cause mortality RRR was $32 \%$ vs placebo while the hospitalization due to heart failure significantly reduced by $35 \%$ with Empagliflozin. Consistent CV Mortality Reduction with Empagliflozin Independently of Baseline HbAlc and Control of HbAlc Inzucchi et al. ${ }^{17}$ (Figure 3) The CV Mortality benefits of Empagliflozin remains independent of baseline $\mathrm{HbA} 1 \mathrm{c}, \mathrm{CVD}$ burden at baseline means regardless of Single Vessel Disease, Multiple vessel disease, MI, Stroke, Heart Failure, PAD, and CKD. The CV mortality benefits with Empagliflozin remain independent of various Cardiovascular / Diabetes drugs used in the background. The CV mortality benefits of Empagliflozin are on top of Standard of Care which means that the Cardio protective benefit has been seen over the best possible $\mathrm{CV}$ medications. The positive CV mortality outcome has opened a new gate for the management of residual CV risk. Due to robust data on cardiovascular protection, US FDA approved an important indication for this class of SGLT2 inhibitor drug Empagliflozin in the category of "Reduce the cardiovascular death in adults with Type II Diabetes USFDA. ${ }^{18}$ Based on the above findings, ADA in 2017 Guidelines endorsed this recommendation of the US FDA.

There were increase adverse event like a genital infection with SGLT2 inhibitors but reversible, reduction in CV events suggest drug cardio protective effects Erdmann et al. ${ }^{19}$ CANVAS Trial on SGLT2 
Inhibitor Canagliflozin was started to Prove the CV Protective effects in Type II Diabetes High-risk Patients who already have cardiovascular disease Neal et al. ${ }^{20}$ MACE 3 point was reduced with Canagliflozin HR 0.86, $\mathrm{P}=0.02$. The concern was a two-fold increase in lower leg amputation (6.3 vs $3.4 / 1000$ patients year and a $26 \%$ increase in bone fracture with treatment. DECLARE TIMI trial with Dapagliflozin has failed to show any significant statistical reduction in 3P MACE but however, has demonstrated a significant $17 \%$ RRR reduction as compared to Placebo in HHF/CV Death \& $27 \%$ statistical significant RRR in HHF as compared to placebo. So All SGLT2 inhibitors have shown a significant reduction in CV Risk, HHF, Worsening of nephropathy but CV mortality \& All-cause mortality outcome is significant with empagliflozin only. In GLP-1RA class only LEADER Trial with Liraglutide LEADER Marso et al. ${ }^{21}$, has shown superiority vs Placebo in CV death reduction as HR was 0.78 , all-cause mortality significantly reduced but not hospitalization, most important benefit can be seen by separation of Kaplan-Meier curves which translate into CV death benefits after 12 months and 18 months for all-cause mortality and hospitalization due to heart failure, due to this US FDA approved a new benefit to reduce MACE in diabetes with establishing cardiovascular disease Victoza. ${ }^{22}$

Consistent CV Mortality Reduction with Empagliflozin Independently of Baseline HbAlc and Control of HbA1c

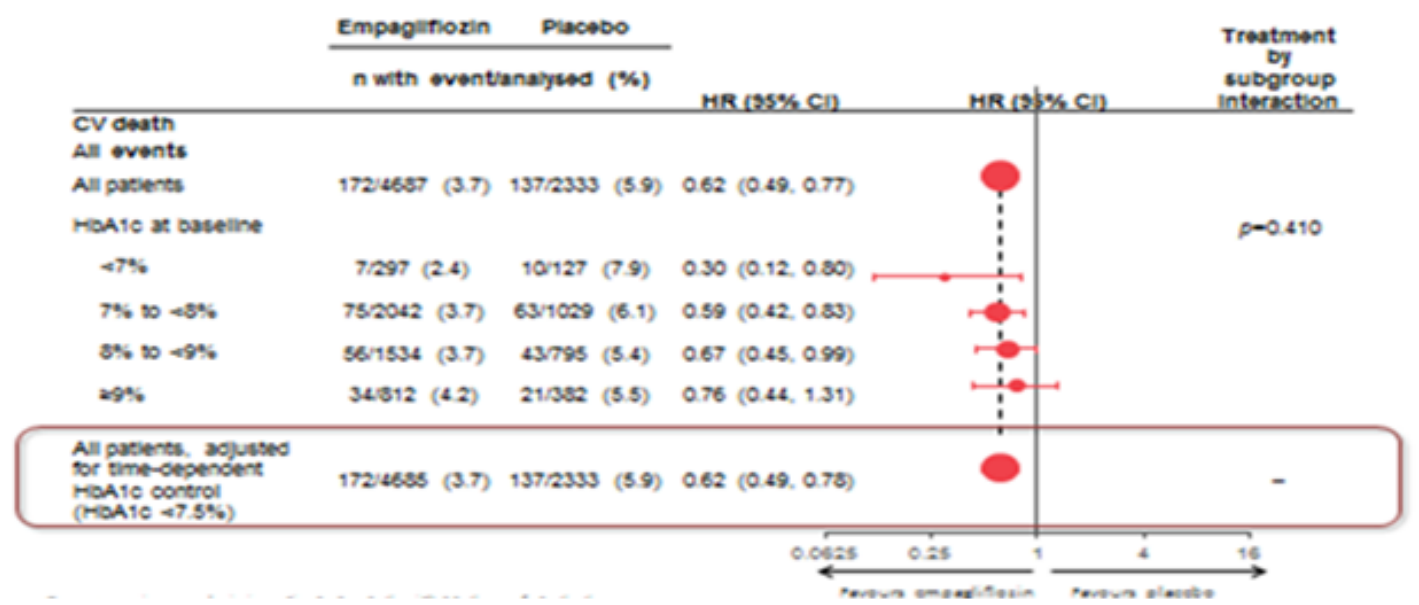

Figure 3 Consistent CV mortality reduction with empagliflozin independency of baseline $\mathrm{HbAlc}$ and control of $\mathrm{HbAlc}$.

Macro vascular complication in type I diabetes and evidence for the treatment \& CVD risk reduction

The cardiovascular complication is long term complication of Type I \& Type II Diabetes, although data on CVD complication for Type II diabetes is more clear than Type I Diabetes in various trials. CVD mean coronary heart disease, PAD peripheral artery disease \& cerebrovascular disease and CVD occurs much earlier in Type I diabetes compare to non-diabetic, EDC study showed that incidence of CAD in Type I adults $28-38$ years is $0.98 \%$ per year and $3 \%$ in more than 55 years Secrest et al. ${ }^{23}$ Relative Risk for CVD is ten times compare to the normal population in type I diabetes adjusted for age Krolewski et al. ${ }^{24}$ As per the UK GPRD study group CVD Events rates occurs 10-15 (HR 9.6 in women \& HR 3.6 in men) years before compare to Non-Diabetes control Soedama et al. ${ }^{25}$ Total CHD Mortality $14-18$ years is $8 \%$ in men and $6 \%$ in women Laing et al. ${ }^{26}$ Stroke is other important cerebrovascular CVD complication is relative low, EURODIAB study reported incidence $0 \mathrm{f} .74 \%$ in a year compare to $0.2 \%$ in General population Roger et al. ${ }^{27}$ Other CVD complication PAD in Type I Diabetes is mainly by Ankle-brachial index lower limb claudication \& non traumatic amputation, lower limb amputation is very high in Sweden as high as $20 \%$ in men \& $11 \%$ in women Jonasson et al. ${ }^{28}$ which is 86 times than of the general population.

In various study on Type I Diabetes it was found that $1 \%$ rise in $\mathrm{HbAlc}$ increase PAD risk by $18 \%$ Adler et al., ${ }^{29}$ but it did not reduce arterial blockage but found to reduce calcification of lower extremities as per the DCCT study Carter et al..$^{30}$ CVD at Subclinical level also causes more Mortality in Type I Diabetes than non-diabetes, Surrogate marker for CVD events like CAC Coronary calcium score is also associated with Type I Diabetes in the CACTI trial Dabelea et al. ${ }^{31}$ Endothelial function is abnormal in Type I Diabetes from very early stage are related to duration of Type I Diabetes which develop in early CHD Singh et al. ${ }^{32}$ Management of CVD Risk in Type I: DCCT Follow up after 17 years with intensive Blood sugar treatment provided reduce CVD events, CV event reduced by $42 \%$ and $\mathrm{MI}$ nonfatal and stroke or CVD death by $57 \%$ than less strict arm Nathan et al. ${ }^{33}$ It has also seen in the DCCT trial that Excess insulin can lead to more weight gain in Type I DM; therefore lifestyle management with intensive changes will be important. Including the DCCT, demonstrate that intensive insulin therapy can lead to excessive weight gain in a subset of patients with T1DM (152). Predicting which individuals with T1DM will go on to become obese would be useful to allow providers to direct intensive lifestyle management efforts appropriately Purnell et al. ${ }^{34}$

EDC Trial suggest LDL $>100 \mathrm{mg} / \mathrm{dl}$ is associated with Increased CVD risk Orchard et al., ${ }^{35}$ which suggest LDL lowering decreases CV events, Therefore statin can be given. Adults with Type I Diabetes with above normal Lipids as in this case should be treated with Statins and other Risk factors like smoking, hypertension, obesity should be controlled. 


\section{Hypoglycemia in type I diabetes}

Hypoglycemia in literature is defined as a blood sugar less than 70 $\mathrm{mg} / \mathrm{dl} \&$ has harmful the consequence in diabetes. The mild episode of Hypoglycemia in Type I Diabetes is around 30 episodes per year/patient and severe hypos is around 3 episodes per year UK HS Group. ${ }^{36}$ Around $2 \%-4 \%$ Mortality in Type I Diabetes is due to Hypoglycemia. As a Consequence of Hypoglycaemia stress hormones \& Count regulatory response especially adrenergic results in heart rate increase and BP which in turn may result in arrhythmia, tachycardia, ventricular and atria ectopic and may leads to Ischemia and death Gill et al. ${ }^{37}$ Recurrent Hypoglycemia has adverse effects on the vasculature in macro and microangiopathy Wright et al., ${ }^{38}$ and increase inflammatory markers like CRP, IL-6, and VEGF which leads to endothelial dysfunction and cardiovascular risk Desouza et al. ${ }^{39}$ Diabetic auto neuropathy is induced by brief exposure to hypoglycaemia and is the additional risk factors for bad cardiovascular outcomes Desouza et al. ${ }^{40}$ In a large study CLARITY TIMI28 has shown the effect of Hypoglycemia on CV event, in hospital patients admitted has the lowest mortality till 30 days with good glycaemic control and high mortality with Hypos and Hyperglycaemia Pinto et al. ${ }^{41}$ All-cause Mortality \& cardiovascular Mortality in intensive in ACCORD \& VADT Trial was more compare to less strict Goal set in the Advance trial Frier et al., ${ }^{42}$ which due to the high rate of Hypoglycemia in ACCORD \& VADT, Specially in ACCORD number of hypos were asymptomatic Bonds et al. ${ }^{43}$ This is very Crucial that Glucose lowering targets are important but Time taken to achieve these targets are equally important as in ACCORD trial target were achieved in 40 months wherein ADVANCE it took 60 months to achieve it In type I Diabetes in ACCORD trial more Hypoglycemia episodes was found in lower HbAlc whereas in Type II Diabetes Severe Hypos were found at higher HbA1c Miller et al. ${ }^{44}$ To summarise Severe Hypoglycemia give rise to cardiovascular mortality in Diabetes. Risk is more when Hypoglycemia episode awareness is less as in Autonomic neuropathy which leads to sudden death. In Diabetes when Hyperglycemia is of long-standing nature and reduction of sudden blood sugar can aggravate cardiovascular with the more episode of hypoglycaemic intervals.

ASPREE trial for Primary Prevention of cardiovascular event in healthy Elderly 19,114 persons were registered in the trial, 9525 assigned to receive aspirin and 9589 to placebo; Follow up after 4.7 years, rate of CVD was 10.7 events per 1000 persons/year after 4.7 years in the aspirin group and 11.3 events in placebo group which was non-significant. ${ }^{45}$ Bleeding was 8.6 events and 6.2 respectively in aspirin and placebo group (HR: 1.38, $\mathrm{P}<0.001$ ).

\section{Summary}

Bleeding risk is more with the use of low dose aspirin in older individual for primary prevention and cardiovascular protection in $\mathrm{CV}$ events reduction were not significantly reduced. We shall be discussing DM1 and CV risk this week. With the increasing survival period of persons with DM1, the risk of CV events is on the rise. But we have seen from the few trials such as DCCT and its extension EDIC that, the risk could be reduced substantially. So please critically appraise these and other similar trials and put forth your views on the subject. CAD Coronary Artery Disease in Type I Diabetes start can be prevented by Aggressive Early treatment as in DCCT Trial 6 years of Intensive treatment with tight Blood sugar control and blood pressure can reduce CAD Monnier et al., ${ }^{46}$ which was later shown by trial as the results of good metabolic memory. IN DCCT/EDIC trial follow up benefit of early intensive therapy in Type I Diabetes Young adults attenuate Atherosclerosis at an early stage which results in decrease $\mathrm{CV}$ events rate later on, but this cannot be replicated in other trial for Type II treatment with Intensive treatment later on as in the VADT trial where $\mathrm{CV}$ events rate was more but all-cause mortality did not differ Gerstein et al. ${ }^{47}$ Like DCCT/EDIC trial, UKPDS with Younger Diabetic patients with newly diagnosed diabetes with absence of CVD events have shown significant decrease in MI and CV mortality in intensive treatment arm UKPDS. 48

A very Interesting results was observed in DCCT/EDIC study in Intensive treatment arm more protection for fatal CAD events than Non-fatal MI, which means in Type I Diabetes HBA1c is strongly predict fatal than nonfatal MI in the future Klein et al ${ }^{49}$ It clearly indicate in Type I Diabetes inflammation, Plaque erosion, Plaque instability are more related to Hyperglycaemia and fatal CAD events Conway et al. $^{50}$ In Conclusion DCCT/EDIC trial includes Type I diabetes Cohort who are followed up for 30 years which undergo intensive diabetes treatment for the ( 6.5 years) has long-term, CV beneficial effects on the incidence of CVD in this cohort and improves life span.

\section{Type I diabetes \& CVD events}

There are many studies which show high Prevalence of CVD in Type I Diabetes, among them, are Pittsburgh Epidemiology of Diabetes complication study EDC, FinnDiane study, EURODIAB and EDIC long term study of DCCT for 30 years. EDC Study reported a CAD 0.36 per person-years by Pambianco. In FinnDiane Type I Study showed 9\% has CVD Gordin et al., ${ }^{51}$ whereas in EDIC study after a follow-up of 17 years CVD events rate were 0.38 per person/per year in intensive arm compare to 0.80 per person/year in Standard arm Nathan et al. ${ }^{52}$ Other large study of CVD in Type I Diabetes, SRLS study in Scottish Type I Diabetes CVD Events for women 3 was higher compare to 2.3 in men group Livingstone et al., ${ }^{53}$ and in GPRD UK study HR for CVD in Women were 7.7 compare to 3.6 for men Soedamah et al. ${ }^{54}$ In the other part of World also like in china the incidence of CV 0.6 per 1000 person-year luk, et al. ${ }^{55}$ and in Saudi Arabia 4\% Type I Diabetes developed CVD Ammari et al. ${ }^{56}$ Therefore CVD is higher in Type I Diabetes than the general population 4-5 folds and CVD the complication is more pronounced in younger women than older age.

\section{Conclusion}

In fact, the ACCORD trial was prematurely stopped owing to an increased cardiovascular mortality rate among intensively managed subjects (HR: 1.35; CI 1.04-1.76; $p=0.02$; It was suggested that this was the result of an increased risk of severe Hypoglycemia due to intensive glucose lowering. Indeed, post hoc analyses from these trials and other studies, e. g. the Outcomes Reduction with an Initial Glargine Intervention (ORIGIN) trial, show that severe Hypoglycemia, regardless of treatment allocation, is associated with an impaired prognosis. DCCT/EDIC trial includes Type I diabetes Cohort who are followed up for 30 years which undergo intensive diabetes treatment for the (6.5 years) has long-term, CV beneficial effects on the incidence of CVD in this cohort and improves life span.

The Macrovascular/microvascular with SGLT2inhibitors \& GLP1RA has been proven in dedicated outcome trials. These benefits have led to the opening of a new era of evidence-based Diabetes Management approach. The newer agents like SGLT2 inhibitors and GLP-1RA has emerged as a preferred partner due to several pleiotropic effects like lower risk of hypoglycemia, weight reduction, 
$\mathrm{CV}$ risk reduction, CV/All-cause mortality, Heart Failure benefits, the improvement in renal outcome. The CV mortality benefits of Empagliflozin is very early and observed within a period of 6 months $\&$ the consistency of Cardio renal benefits is very surprising as it remains independent of $\mathrm{BP}$ control, LDL, HbAlc , CVD , CKD, baseline medications, etc. and remains the only OAD for reducing the risk of $\mathrm{CV}$ death. There are numerous mechanisms behind cardio renal benefits are proposed but mechanism remains unknown. The selection of Diabetes medication has to be based on various compelling need or comorbidities. The unmet need for Heart Failure \& CKD/DKD has led the foundations of dedicated Heart Failure and Renal Program with Empagliflozin and other SGLT2 inhibitors. So the emergence of management of Metabolic Cardio-Renal axis with SGLT2 inhibitors /GLP-1RA is going to be very exciting because the one Diabetes medication acting as multiple interventions \& SGLT2 inhibitors/GLP1RA will challenge the status quo of Metformin in near future. The ongoing trials with SGLT2 inhibitors inT1DM can address a billiondollar question like Can SGLT2 inhibitors offer Cardio-Renal benefits in T1DM and can it be beneficial in reducing the frequency of insulin/ dose of insulin \& risk of weight gain.

\section{Acknowledgments}

None.

\section{Conflicts of interest}

The author has no conflicts of interest.

\section{Funding}

None.

\section{References}

1. Morrish NJ, Wang SL, Stevens LK, et al. Mortality and causes of death in the WHO Multinational Study of Vascular Disease in Diabetes. Diabetologia. 2001;44(Suppl 2):S14-S21.

2. Caro JJ, Ward AJ, O’Brien JA. Lifetime costs of complications resulting from type 2 diabetes in the U.S. Diabetes Care. 2002;25(3):476-481.

3. Ingelsson E, Sullivan LM, Murabito JM, et al. Prevalence and prognostic impact of subclinical cardiovascular disease in individuals with the metabolic syndrome and diabetes. Diabetes. 2007;56(6):1718-1726.

4. Low Wang CC eta al. Atherosclerotic Cardiovascular Disease and Heart Failure in Type 2 Diabetes Mellitus - Mechanisms, Management, and Clinical Considerations. Circulation. 2016;133:2450-2502.

5. Dandamudi S, Slusser J, Mahoney DW, et al. The prevalence of diabetic cardiomyopathy: a population-based study in Olmsted County, Minnesota. J card Fail. 2014;20(5):304-309

6. Afkarian M, Sachs MC, Kestenbaum B, et al. Kidney disease and increased mortality risk in type 2 diabetes. $J$ Am Soc Neprol. 2013;24(2):302-308.

7. Di Angelantonio E, Kaptoge S, Wormser D, et al. Association of Cardiometabolic Multimorbidity with Mortality. JAMA. 2015;314(1):5260 .

8. Hu FB, Stampfer MJ, Haffner SM, et al. Elevated risk of cardiovascular disease prior to clinical diagnosis of type 2 diabetes. Diabetes Care. 2002;25(7):1129-1134.

9. Bajaj HS, Zinman B, Verma S. Antihyperglycemic agents and cardiovascular outcomes: recent insights. Curr Opin Cardiol. 2017;32(5):642-650.
10. Chew EY, Ambrosius WT, Davis MD, et al. Effects of medical therapies on retinopathy progression in type 2 diabetes. $N$ Engl J Med. 2010;363(3):233-244

11. National Institutes of Health NIH. For Safety, NHLBI changes intensive blood sugar treatment strategy in clinical trial of diabetes and cardiovascular disease. 2018.

12. Gerstein HC, Mann JF, Yi Q, et al. Albuminuria and risk of CV events, death, and heart failure in diabetic and non-diabetic individuals. JAMA. 2001;286(4):421-426.

13. National Cholesterol Education Program NCEP. Third Report of the National Cholesterol Education Program (NCEP) Expert Panel on Detection, Evaluation, and Treatment of High Blood Cholesterol in Adults (Adult Treatment Panel III) final report. Circulation. 2002;106(25):3143-3421.

14. Holman RR, Paul SK, Bethel MA, et al. 10-year follow-up of intensive glucose control in type 2 diabetes. N Engl J Med. 2008;359(15):15771589 .

15. Duckworth W, Abraira C, Moritz T, et al. Glucose control and vascular complications in veterans with type 2 diabetes. $N$ Engl $\mathrm{J}$ Med. 2009;360(2):129-139.

16. Zinman B, Wanner C, Lachin JM, et al. Empagliflozin, cardiovascular outcomes, and mortality in type 2 diabetes. $N$ Engl J Med. 2015;373(22):2117-2128.

17. Inzucchi SE, Kosiborod $\mathrm{M}$, Fitchett $\mathrm{D}$, et al. Improvement in Cardiovascular Outcomes With Empagliflozin Is Independent of Glycemic Control. Circulation. 2018;138(17):1904-1907.

18. U.S. Food and Drug Administration. FDA approves Jardiance to reduce cardiovascular death in adults with type 2 diabetes. 2016.

19. Erdmann E, Califf R, Gerstein HC, et al. Effects of the dual peroxisome proliferator-activated receptor activator aleglitazar in patients with type 2 diabetes mellitus or prediabetes. Am Heart J. 2015;170(1):117-122.

20. Neal B, Perkovic V, de Zeeuw D, et al. Rationale, design, and baseline characteristics of the Canagliflozin Cardiovascular Assessment Study (CANVAS)--a randomized placebo-controlled trial. Am Heart $J$. 2013;166(2):217-223.

21. Marso SP, Daniels GH, Brown-Frandsen K, et al. Liraglutide and cardiovascular outcomes in type 2 diabetes. $N$ Engl $\mathrm{J}$ Med. 2016;375(4):311-322.

22. Victoza liraglutide injection $1.2 \mathrm{mg} / 1.8 \mathrm{mg}$. Plainsboro, NJ, Novo Nordisk; 2017.

23. Secrest AM, Becker DJ, Kelsey SF, et al. Cause-specific mortality trends in a large population-based cohort with long-standing childhood-onset type 1 diabetes. Diabetes. 2010;59(12):3216-3222.

24. Krolewski AS, Kosinski EJ, Warram JH, et al. Magnitude and determinants of coronary artery disease in juvenile-onset, insulindependent diabetes mellitus. Am J Cardiol. 1987;59(8):750-755.

25. Soedamah-Muthu SS, Chaturvedi N, Schalkwijk C, et al. Soluble vascular cell adhesion molecule-1 and soluble E-selectin are associated with micro- and macrovascular complications in type 1 diabetic patients. J Diabetes Complications. 2006;20(3):188-195.

26. Laing SP, Swerdlow AJ, Slater SD, et al. Mortality from heart disease in a cohort of 23,000 patients with insulin-treated diabetes. Diabetologia. 2003;46(6):760-765.

27. Roger VL, Go AS, Lloyd-Jones DM, et al. Heart disease and stroke statistics-2012 update: a report from the American Heart Association. Circulation. 2012;125(1):e2-e220. 
28. Jonasson JM, Ye W, Sparén P, et al. Risks of nontraumatic lowerextremity amputations in patients with type 1 diabetes: a populationbased cohort study in Sweden. Diabetes Care. 2008;31(8):1536-1540.

29. Adler AI, Erqou S, Lima TA, et al. Association between glycated haemoglobin and the risk of lower extremity amputation in patients with diabetes mellitus-review and meta-analysis. Diabetologia. 2010;53(5):840-849.

30. Carter RE, Lackland DT, Cleary PA, et al. Intensive treatment of diabetes is associated with a reduced rate of peripheral arterial calcification in the Diabetes Control and Complications Trial. Diabetes Care. 2007;30(10):2646-2648.

31. Dabelea D, Kinney G, Snell-Bergeon JK, et al. Effect of type 1 diabetes on the gender difference in coronary artery calcification: a role for insulin resistance? The Coronary Artery Calcification in Type 1 Diabetes (CACTI) Study. Diabetes. 2003;52(11):2833-2839.

32. Singh TP, Groehn H, Kazmers A. Vascular function and carotid intimalmedial thickness in children with insulin-dependent diabetes mellitus. $J$ Am Coll Cardiol. 2003;41(4):661-665.

33. Nathan DM, Cleary PA, Backlund JY, et al. Intensive diabetes treatmen and cardiovascular disease in patients with type 1 diabetes. $N$ Engl J Med. 2005;353(25):2643-2653.

34. Purnell JQ, Hokanson JE, Marcovina SM, et al. Effect of excessive weight gain with intensive therapy of type 1 diabetes on lipid levels and blood pressure: results from the DCCT. Diabetes Control and Complications Trial. JAMA. 1998;2820(2):140-146.

35. Orchard TJ, Forrest KY, Kuller LH, et al. Lipid and blood pressure treatment goals for type 1 diabetes: 10-year incidence data from the Pittsburgh Epidemiology of Diabetes Complications Study. Diabetes Care. 2001;24(6):1053-1059.

36. UK Hypoglycaemia Study Group. Risk of hypoglycemia in types 1 and 2 diabetes: effects of treatment modalities and their duration. Diabetologia. 2007;50(6):1140-1147.

37. Gill GV, Woodward A, Casson IF, et al. Cardiac arrhythmia and nocturnal hypoglycemia in type 1 diabetes - the 'dead in bed' syndrome revisited. Diabetologia. 2009;52(1):42-45.

38. Wright RJ, Frier BM. Vascular disease and diabetes: is hypoglycemia an aggravating factor? Diabetes Metab Res Rev. 2008;24(5):353-363.

39. Desouza CV, Bolli GB, Fonseca V. Hypoglycemia, diabetes, and cardiovascular events. Diabetes Care. 2010;33(6):1389-1394.

40. Desouza C, Salazar H, Cheong B, et al. Association of hypoglycemia and cardiac ischemia: a study based on continuous monitoring. Diabetes Care. 2003;26(5):1485-1489.

41. Pinto DS, Kirtane AJ, Pride YB, et al. Association of blood glucose with angiographic and clinical outcomes among patients with ST-segment elevation myocardial infarction (from the CLARITY-TIMI-28 study). Am J Cardiol. 2008;101(3):303-307.

42. Frier BM, Schernthaner G, Heller SR. Hypoglycemia and cardiovascular risks. Diabetes Care. 2011;34(Supp1 2):S132-S137.

43. Bonds DE, Miller ME, Bergenstal RM, et al. The association between symptomatic, severe hypoglycemia and mortality in type 2 diabetes: retrospective epidemiological analysis of the ACCORD study. BMJ. 2010;340:b4909.
44. Miller ME, Bonds DE, Gerstein HC, et al. ACCORD Investigators: The effects of baseline characteristics, glycemia treatment approach, and glycated haemoglobin concentration on the risk of severe hypoglycemia: post hoc epidemiological analysis of the ACCORD study. BMJ. 2010;340:b5444.

45. McNeil JJ, Wolfe R, Woods RL, et al. Effect of Aspirin on Cardiovascular Events and Bleeding in the Healthy Elderly. $N$ Engl $J$ Med. 2018;379(16):1509-1518.

46. Monnier VM, Bautista O, Kenny D, et al. Skin collagen glycation, glycoxidation, and crosslinking are lower in subjects with long-term intensive versus conventional therapy of type 1 diabetes: relevance of glycated collagen products versus HbAlc as markers of diabetic complications. DCCT Skin Collagen Ancillary Study Group, Diabetes Control and Complications Trial. Diabetes. 1999;48(4):870-880.

47. Gerstein HC, Miller ME, Byington RP, et al. Effects of intensive glucose lowering in type 2 diabetes. $N$ Engl J Med. 2008;358(24):2545-2559.

48. UK Prospective Diabetes Study (UKPDS) Group. Intensive bloodglucose control with sulphonylureas or insulin compared with conventional treatment and risk of complications in patients with type 2 diabetes (UKPDS 33). Lancet. 1998;352(9131):837-853.

49. Klein BE, Klein R, McBride PE, et al. Cardiovascular disease, mortality, and retinal microvascular characteristics in type 1 diabetes: Wisconsin epidemiologic study of diabetic retinopathy. Arch Intern Med. 2004;164(17):1917-1924.

50. Conway B, Costacou T, Orchard T. Is glycaemia or insulin dose the stronger risk factor for coronary artery disease in type 1 diabetes?. Diab Vasc Dis Res. 2009;6(4):223-230.

51. Gordin D, Wadén J, Forsblom C, et al. Pulse pressure predicts incident cardiovascular disease but not diabetic nephropathy in patients with type 1 diabetes (The FinnDiane Study). Diabetes Care. 2011;34(4):886-891.

52. Nathan DM, Cleary PA, Backlund JY, et al. Intensive diabetes treatment and cardiovascular disease in patients with type 1 diabetes. $N$ Engl J Med. 2005;353(25):2643-2653.

53. Livingstone SJ, Looker HC, Hothersall EJ, et al. Risk of cardiovascular disease and total mortality in adults with type 1 diabetes: Scottish registry linkage study. PLoS Med. 2012;9(10):e1001321.

54. Soedamah-Muthu SS, Fuller JH, Mulnier HE, et al. High risk of cardiovascular disease in patients with type 1 diabetes in the U.K.: a cohort study using the general practice research database. Diabetes Care. 2006;29(4):798-804.

55. Luk AO, Lau ES, So WY, et al. Prospective study on the incidences of cardiovascular-renal complications in Chinese patients with youngonset type 1 and type 2 diabetes. Diabetes Care. 2014;37(1):149-157.

56. Ammari F. Long-term complications of type 1 diabetes mellitus in the western area of Saudi Arabia. Diabetol Croat. 2004;33(2):59-63. 